\title{
Organic brake friction composite materials: impact of mixing duration on microstructure, properties, tribological behavior and wear resistance
}

\author{
Fatma Makni ${ }^{1,2}$, Anne-Lise Cristol ${ }^{2}$, Riadh Elleuch ${ }^{1}$ and Yannick Desplanques ${ }^{2}$ \\ ${ }^{1}$ Laboratory of Electro-Mechanical Systems (LASEM), National School of Engineers of Sfax (ENIS), \\ University of Sfax, Sfax, Tunisia \\ ${ }^{2}$ Univ. Lille, CNRS, Centrale Lille, UMR 9013 - LaMcube - Laboratoire de Mécanique \\ Multiphysique Multiéchelle, F-59000 Lille, France
}

\begin{abstract}
The lack of knowledge on the link between the manufacturing process and performances constitutes a major issue of brake lining development. This study focuses on the effect of mixing duration on properties and tribological behavior of organic friction composite materials. The adopted methodology is based on efficient simplified formulations to limit synergic effects by the reduction of number and size distribution of constituents. Microstructural characteristics are analyzed and correlated to thermo physical and mechanical properties. Wear mechanisms and tribological behavior are studied in relation with the given microstructure and material properties.

In the elaboration process, mixing duration has an impact on particle distribution and fibre arrangement. Distribution and size of fibre entanglements are found to cluster carbonaceous particles, which creates bulk thermal bridges improving thermal conductivity. Moreover, rockwool fibre arrangements affect density, porosity and thermo-physical properties. In addition, mixing duration disrupts cohesion of fibre bundles with the matrix, affecting compressive modulus and wear behaviour. This microstructural defect fosters an abundant third-body source flow, which results in a high wear flow. Porosities induced by fibre entanglements, presenting large and irregular size and distribution on the friction surface, lead to a low wear resistance and change the stability of friction.
\end{abstract}

\section{Keywords}

Brake friction materials, mixing duration, properties, tribological behavior, wear 


\section{Introduction}

Friction materials present important parts of the brake system which are extensively used in the automotive, railway, and other transport fields $[1,2]$. These brake friction materials have complex formulations which shoud fulfil several performance requirements such as stable friction coefficient, low wear, low fade, less brake vibration and noise and environmental friendliness [3,4]. These requirements are affected by the formulation, the selection of the constituents and the setting of manufacturing parameters. Several studies were focused on the optimization of friction materials manufacturing process [5, 6, 7, 8]. For example, Ertan and Yavuz [9] investigated the effects of the manufacturing parameters on the tribological behaviour of friction materials in order to achieve optimal manufacturing parameters and thus improve their performances. Kim, et al. [10] used Taguchi analytical methodology to explore the impact of manufacturing on the tribological behavior of brake friction materials. The impact of types and the relative amounts of raw material constituents on the friction material properties and performances have been also widely studied [11,12].

Composite friction material is essentially a multi-consitutent material which is highly heterogeneous. Kim et al. [13] revealed that effectiveness of the friction was inversely proportional to the size of the abrasive, and concluded that smaller zircon particles generate friction instability. Studies on the relationship between constituent arrangement and distribution and the resulting microstructure, properties and performances of brake friction materials remain are not carried out yet.

Furthermore, few researches were focused on the impact of the manufacturing process on the resulting microstructure $[14,15]$. In fact, microstructural characteristics namely arrangement of fibres and distribution of constituents and porosities induced by the manufacturing process are still not well investigated. The available reported data are not very detailed and concern only average fibre fractions and void contents and some representative microstructural analysis. These information remain insufficient for detailed numerical analysis which requires creating representative volume elements that reprent the realistic microstructure

As we have mentioned, there has been some intereset on the impact of the manufacturing process namely hot moulding and post curing on friction materials properties and performances [16, 17]. However, the mixing step is still not well investigated. Mixing is the first step of the brake pad production. This operation depends on several factors: order of incorporation of ingredients, mixing duration and speed and loading volume. Each parameter has an impact on mixture quality, and thus defines the resulting microstructure and properties of friction materials. However, the impact of this step parameters on microstructural, thermo-physical and mechanical properties and tribological behaviour of friction materials remains not understood. Indeed, no correlation were revealed between the resulting microstructure, properties and performances of brake materials [18].

Thus, this paper aims to study the impact of mixing duration on the resulting microstructure, properties and tribological behaviour of friction materials. Besides, this work helps to establish the link between microstructural characteristics induced by mixing duration, thermo physical and mechanical properties, friction behaviour and wear mechanisms of composite friction materials. To achive these objectives, an experimental methodology based on material simplification is adopted. Thorough microstructural analyses using $2 \mathrm{D}$ and $3 \mathrm{D}$ characterizations are performed and then correlated to the resulting properties and tribological and wear behaviour of the studied materials. 


\section{Materials and methods}

\subsection{Simplified materials}

The adopted simplification methodology is based on the reduction of constituent number and size distribution while retaining their efficiency in braking situations $[17,19]$. The aim of this approach is to limit synergistic effects and facilitate identifying each component of the microstructure and thus to access to friction materials properties and performances. Six constituents were retained (phenolic resin, calcium carbonate, rubber, graphite, alumina and rockwool fibers) with reduced size distribution as shown in Table 1. Resin, calcium carbonate and alumina present very fine particles (mean diameter < $6 \mu \mathrm{m}$ ) and constitute the matrix of these composite materials. This material simplification was detailed in previous work [20]. The elaboration process of brake friction materials includes several steps (mixing, cold preforming, hot molding, post curing). In this study, the impact of mixing step on the resulting microstructure and properties of friction materials was investigated. Parameters of mixing were studied in previous work [15]. This latter suggested order and duration of constituents introduction sequences which permits to obtain good distribution of particles. According to this study, two materials were elaborated depending on mixing duration of each constituent introduction sequence. The simplified materials were elaborated using a laboratory mixer which reproduces the same mixing mechanisms of the industrial one. Constituents for the two materials were incorporated in the mixture with same defined order. The first material, referenced as M1, was performed using a defined introduction sequence of constituents with total mixing duration of $706 \mathrm{~s}$. The second, referenced as M2, was elaborated with the same introduction sequences but with a very short mixing duration of $40 \mathrm{~s}$ (Table 2). This short duration was fixed to obtain a sufficient brazing and a reasonable repartition of constituents. Before elaborating the mixture of $\mathrm{M} 2$, components namely graphite and rubber particles were pre-coated by matrix particles to guarantee the cohesion of the final material [21]. The adopted methodology aims to establish the link between microstructural characteristics induced by mixing step, properties and tribological behavior of composite friction materials.

Table 1. Formulation and constituent size for simplified materials

\begin{tabular}{cccc} 
Class & Constituent & Weight $(\%)$ & $\begin{array}{c}\text { Mesh opening size } \\
(\mu \mathrm{m})\end{array}$ \\
\hline Binder & Phenolic resin & 15.3 & - \\
\hline Filler & Calcium carbonate & 21.3 & - \\
\hline Abrasive & Alumina & 1.2 & - \\
\hline Lubricant & Graphite & 11.9 & $212-300$ \\
\hline Friction modifier & Rubber & 11.3 & $325-400$ \\
\hline Fiber & Rockwool fibers & 39.1 & Fibers $<400$
\end{tabular}

After mixing, a succession of steps was carried out: first, a cold preforming, then a hot molding at a curing temperature of $140^{\circ} \mathrm{C}$ during 11 min under pressure of 200 bars, and finally a post-curing at $160^{\circ} \mathrm{C}$ for 8 hours. At the end of the manufacturing process, several finishing operations were performed 
to get a flat plate of $16 \mathrm{~mm}$ thick and $400 * 400 \mathrm{~mm}$ width. For this work, specimens were sampled from the resulting plates are cylindrical with a parallel axe to the normal direction of the manufactured plate. This sampling direction considers the transverse isotropy of microstructure and properties of these materials [17]. The normal direction corresponds to the direction of compression during preforming and hot molding steps which present the direction of the normal load application on brake lining in use.

Table 2. Mixing parameters of simplified material constituents

\begin{tabular}{|c|c|c|c|}
\hline & & Material M1 & Material M2 \\
\hline Sequences & Blended constituents & \multicolumn{2}{|c|}{ Duration $(\mathrm{s})$} \\
\hline 1 & $\begin{array}{c}50 \% \text { calcium carbonate }+ \\
50 \% \text { rubber }+ \text { alumina }\end{array}$ & 52 & 4 \\
\hline 2 & $50 \%$ resin $+50 \%$ rubber & 88 & 8 \\
\hline 3 & $\begin{array}{c}50 \% \text { calcium carbonate }+ \\
50 \% \text { graphite }\end{array}$ & 54 & 4 \\
\hline 4 & $50 \%$ resin $+50 \%$ graphite & 52 & 4 \\
\hline 5 & Rockwool fibers & 460 & 20 \\
\hline & tal mixing duration & 706 & 40 \\
\hline
\end{tabular}

\subsection{Microstructure characterizations}

\subsubsection{D microstructural analysis}

In the first step, characterization of microstructure was carried out using Scanning Electron Microscopy (SEM). Specimens for microstructural examination were polished following standard procedures. The aim of this investigation is to provide information about constituent distribution and microstructural characteristics of the resulting materials.

\subsubsection{D microstructural analysis}

The size distribution, arrangement and spatial repartition of constituents of the two materials M1 and M2 were analyzed by 3D X-ray tomography using a laboratory equipment with a procedure already described in detail in Makni et al. [20]. Cylindrical specimen with a length of $16 \mathrm{~mm}$ and a radius of $6 \mathrm{~mm}$ were sampled from each material in the normal direction ( $\mathrm{Z}$ direction) and scanned using an $\mathrm{X}$ ray microtomographic apparatus: Ultratom, RxSolution $(\mathrm{C}$. The transmission X-ray tube (W target) was operated at a voltage of $160 \mathrm{kV}$ and an intensity of $275 \mu \mathrm{A}$. The voxel size was set at $4.4 \mu \mathrm{m}^{3}$. Reconstructed images were analyzed using Image J 1.46r software of the Wayne Rasband National Institutes of Health USA (http://imagej.nih.gov/ij). This technique allows to evaluate particle distribution and arrangements in the material volume and mark internal defects and constituents of interest [22]. To assess constituent spatial distribution in the studied materials volume, 3D analyses were carried out on specimens with a radius of $16 \mathrm{~mm}$ and length of $16 \mathrm{~mm}$.

\subsection{Thermo physical characterization}

Physical (density and porosity), thermal (thermal conductivity, specific heat capacity and thermal effusivity) and thermal induced (thermal expansion) properties for M1 and M2 were studied. Density was measured using Archimedes' principle. Specimens were weighted in air then in water using a 
Mettler Toledo electronic balance with $0.5 \mathrm{~g}$ accuracy. Theorotical porosity was calculated using the following expression:

$$
\begin{aligned}
& \text { Porosity }(\%)=1-\text { intensification rate }(\%) \\
& \text { Intensification rate }(\%)=\frac{\rho m}{\sum \frac{m i x \rho i}{100}} \times 100
\end{aligned}
$$

Where $\rho_{\mathrm{m}}$ presents the bulk specific density $\left(\mathrm{g} / \mathrm{cm}^{3}\right), \mathrm{m}_{\mathrm{i}}$ corresponds to the weight $(\%)$ of each ingredient of the formulation and $\rho_{i}$ presents the absolute density of each ingredient of the formulation $\left(\mathrm{g} / \mathrm{cm}^{3}\right)$. Thermal Expansion $(\alpha)$, thermal conductivity $(\lambda)$ and specific heat capacity $(C p)$ measurements were performed according to defined parameters and using specific equipments detailed in previous study [20]. The thermal effusivity $(\varepsilon)$ was calculated using values of the measured conductivity, density and specific heat capacity as follows :

$$
\varepsilon=\sqrt{\rho \lambda C p}
$$

Results of theses characterizations are reported in Table 3. Three samples of each material were tested, and an average value of measures are given with a standard deviation value.

\subsection{Mechanical test}

Simplified materials were characterized for mechanical properties using a compression test. This latter was performed on an Instron electromechanical machine with a load capacity of $10 \mathrm{kN}$. The specimens are parallelipedic with a dimension of $20 \mathrm{~mm}$ and a height of $16 \mathrm{~mm}$. The deviation of parallelism of the top and bottom faces, in contact with the non-rotated platens, is less than $20 \mu \mathrm{m}$. Both contact faces of the sample are lubricated with graphite to promote sample-plate sliding and limit its barrel deformation. A speckle is applied on one side face with the airbrush [21], the digital image acquisition is performed with a Ximea camera at a frequency of 5 frames/sec. In order to have a uniform illumination of the speckles of the studied face, a projector is positioned at a distance of $4 \mathrm{~m}$, a black cloth masks the organs of the machine to reduce the light reflections on the sample. Samples were machined in the normal direction to the plane of brake friction materials. Three stress levels of 2,5 and $10 \mathrm{MPa}$ were performed for samples. Each stress level was applied five times. The speed of plateaus displacement is set at $0.01 \mathrm{~mm} / \mathrm{s}$ [20]. Digital Image Correlation (DIC) method was employed to identify strain/ stress localizations [23]. To achieve post treatment of all results, Digital Image Correlation (platform yadics, http://yadics.univ-lille1.fr ) was used. Compressive modulus was estimated using measurement of strain fields (Table 4) [24]. Only Strain fields for $10 \mathrm{MPa}$, given in the compression direction (Ezz (\%)), are presented in Figure 9.

\subsection{Evaluation of tribological behavior}

\subsubsection{Tribometer description}

The evaluation of the tribological behavior was performed by the means of friction test. This latter was carried out on a pin-on-disc tribometer with a plane contact (Figure 1). This apparatus is composed of a spindle, at the end of which is mounted the test disc, driven in rotation by a brushless electric motor which guarantees a great regularity of the speed, and of a device of load application and forces measurement. This device consists of a clamp with a diameter of $16 \mathrm{~mm}$ in which the friction material 
sample is fixed, mounted on a slider driven by an elastic clearance free connection for the load application. The load is applied by the compression of a helical spring of stiffness $50 \mathrm{~N} / \mathrm{mm}$. The normal and tangential forces are measured by two strain-gauge sensors implanted onto a testing cell. These measurements permit to calculate the friction coefficient.

\subsubsection{Experimental protocol}

The friction tests were carried out with a pin made of friction material rubbing against a grey cast iron disc (Figure 1). The pin has a cylindrical shape with a diameter of $16 \mathrm{~mm}$ and a height of $16 \mathrm{~mm}$ and the disc track has an average friction radius of $100 \mathrm{~mm}$ and a thickness of $20 \mathrm{~mm}$. The disc is made of lamellar graphite cast iron (ENGJL 250). The pin surface was rectified, and surface of the disc was polished to grade 500 and then 1200, at $200 \mathrm{rpm}$ [17]. The out-of-plane runout of the disc friction track was controlled so that it is limited at few tens of micrometers. Tribological tests were performed under low energy conditions at a rotating speed of $600 \mathrm{tr} / \mathrm{min}$, i.e. a sliding speed of $6.3 \mathrm{~m} / \mathrm{s}$, and applied load of $0.5 \mathrm{MPa}$.

Friction tests were interrupted at different durations while taking care not to exceed $100^{\circ} \mathrm{C}$ for the disc temperature in order to correlate the evolution of the friction coefficient to the tribological mechanisms and phenomena induced during the friction.

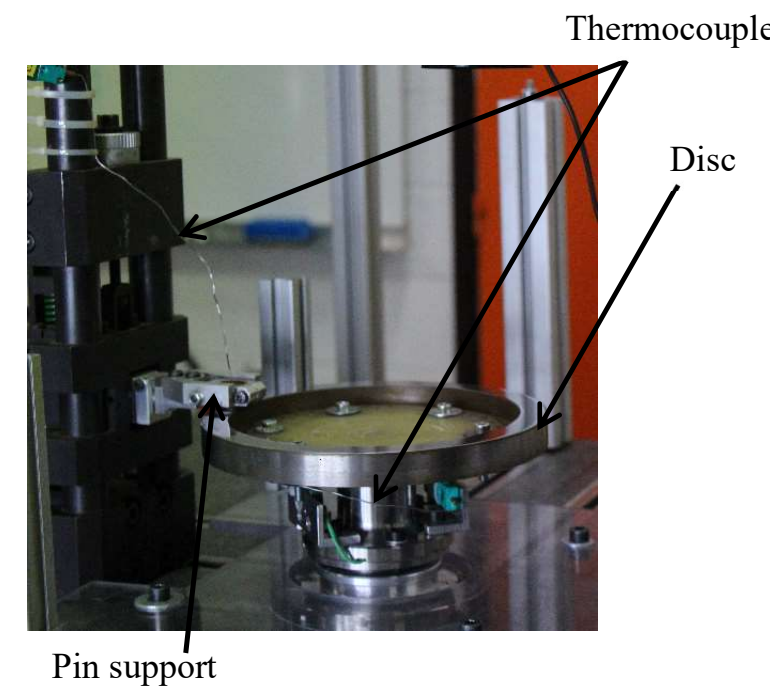

Figure 1. Pin-on-disc tribometer

The retained duration was 5 minutes. For each material, five sequences of run-in followed up by a sliding test of 5 minutes were performed. Disc and pin temperatures were measured by the means of K-type thermocouples located on the average friction radius respectively $2 \mathrm{~mm}$ and $3 \mathrm{~mm}$ below the friction surface $[19,25]$.

\subsubsection{Evaluation of wear behavior}

The wear mechanisms induced by friction are investigated using SEM observations and EDS analysis of the rubbed surfaces. EDS analysis of the chemical composition of the flat plates at different points for each material was performed to reveal the wear behavior of the studied materials. Results of this analysis were listed in Table 5. To estimate a wear rate, the pin thickness was measured before and after each friction test (Table 6). 


\section{Results and discussion}

\subsection{Microstructure}

Figure 2 illustrates different components of the two materials: fine particles (resin, calcium carbonate and alumina) constitute the matrix which embeds the other constituents (rubber, graphite, rockwool fibers (shots and fibers)). Micrographs of M2 display more numerous fiber entanglements of rockwool fibers which present bigger and variable sizes than those of M1 (Figure 2 (b)). Moreover, they seem to be less embedded in the matrix. Fibers appear to be mostly emerged from the matrix for M2. SEM micrography of M2 (Figure 2 (b) provides evidence for the poor interface adhesion between rockwool fibers and the matrix. Morphology of fiber bundles for the two materials seem to be similar since they result from the re-entanglement of fibers during the mixing step [20].

Several agglomerated particles were revealed in M2 (Figure 3 (b)). These agglomerations correspond to matrix particles which indicates that they were not well dispersed in this material. Figure 3 shows a lack of cohesion between rubber particles and the matrix which seems to be more pronounced in M2.

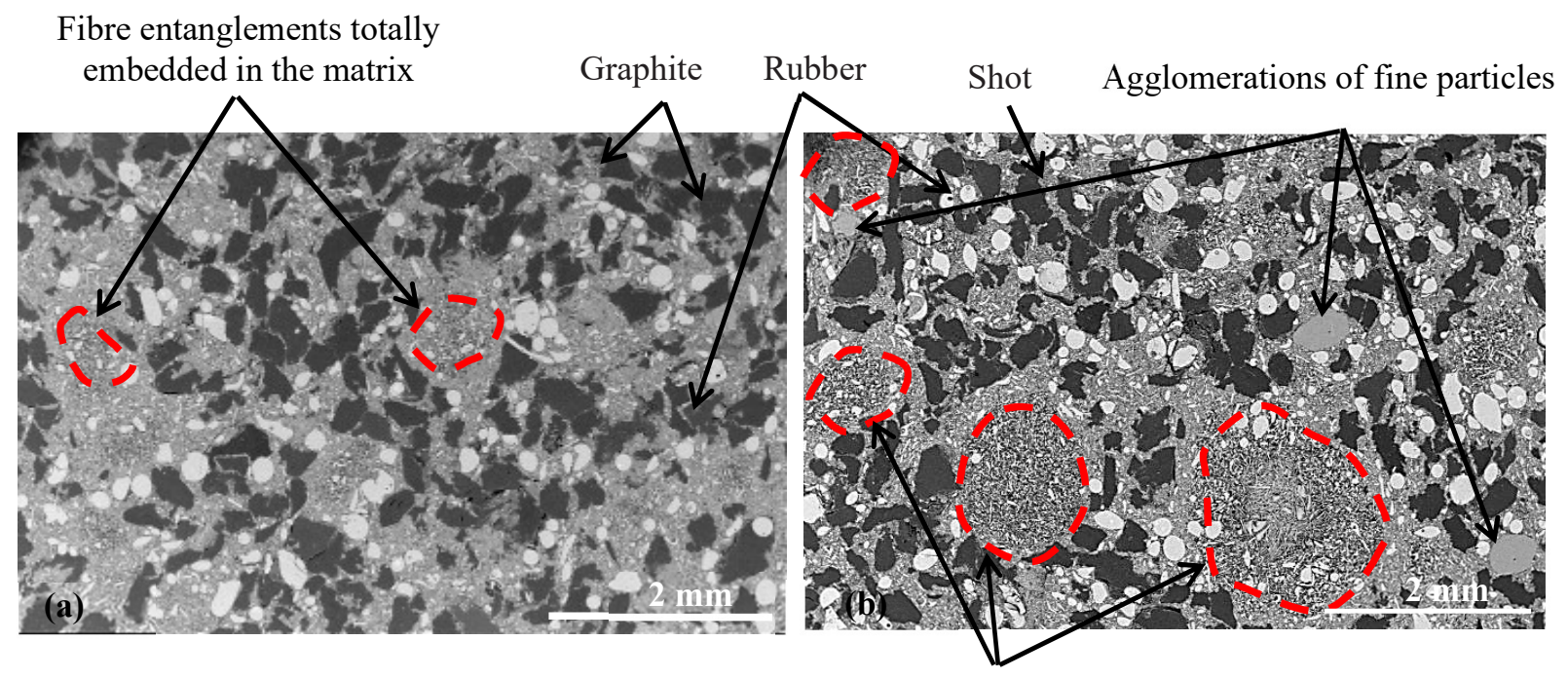

Fibre entanglements partially embedded in the matrix

Figure 2. Microstrucure of materials (a) M1 and (b) M2 (SEM-BSE)

Lack of cohesion between rubber particles and matrix

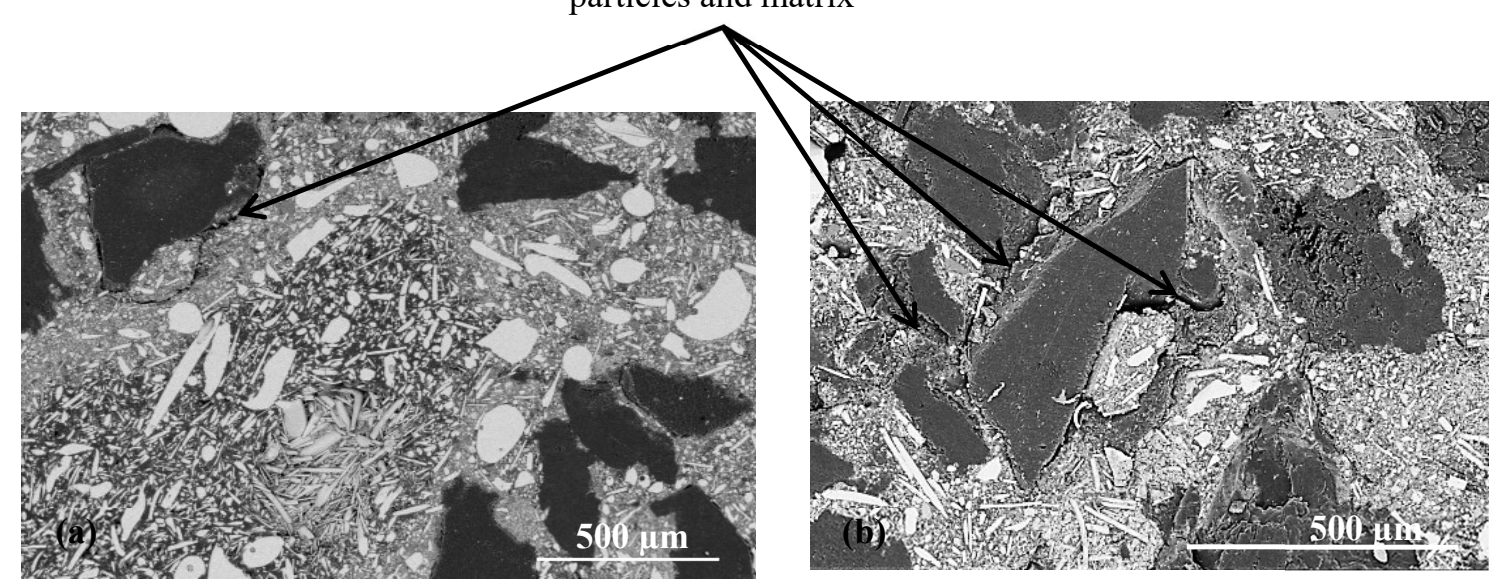


Figure 3. Microstructural defects in materials (a) M1 and (b) M2 (SEM-BSE)

\subsubsection{Spatial constituent distribution}

It should be mentioned that, in all 2D and 3D visualizations given by Figure 4 and Figure 5, fiber entanglements and carbonaceous particles are marked with respectively orange and green colors. Shots and matrix are highlighted in respectively yellow and gray colors. 2D orthogonal and longitudinal visualizations are displayed in respectively the $\mathrm{XY}$ and the $\mathrm{XZ}$ planes.

3D visualizations shown in Figure 4 and Figure 5 present the spatial distribution of constituents in the two materials volume. Figure 5 reveals the presence of several rockwool fiber entanglements in the volume of the M2 which are more numerous and bigger than those in M1. These entanglements shape is irregular and their size is variable, as in M1. The longitudinal sections in Figure 5 (b) show that fiber entanglements are randomly dispersed throughout the height of the sample, their size can exceed $3 \mathrm{~mm}$. As for the carbonaceous particles, they appear most often grouped and interconnected on different sections of M2. For M, inter-particle distances of carbonaceous particles are more important and their interfaces with matrix are more numerous.

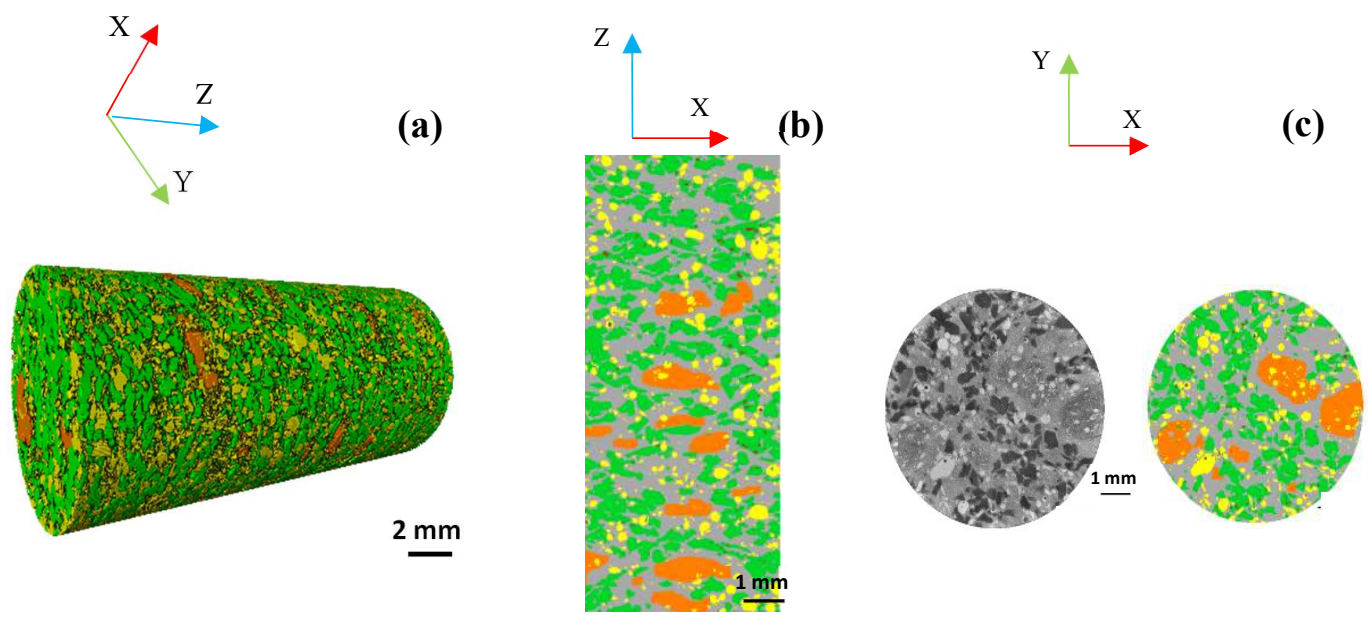

Figure 4. Spatial constituent distribution in M1

$3 \mathrm{D}$ visualization, $2 \mathrm{D}$ longitudinal visualization in $\mathrm{XZ}$ plane, $2 \mathrm{D}$ orthogonal visualization in $\mathrm{XY}$ plane

Fiber bundles (orange), carbonaceous particles (green), matrix (gray), shots (yellow), voids (red) 


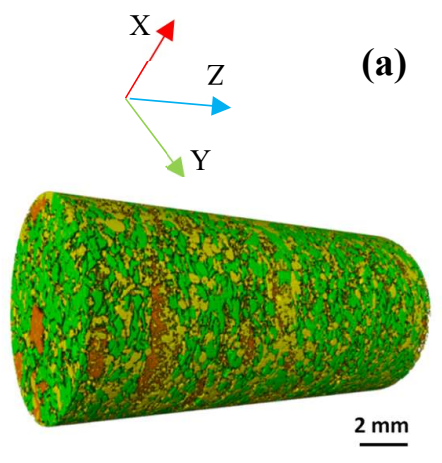

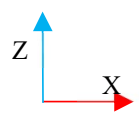

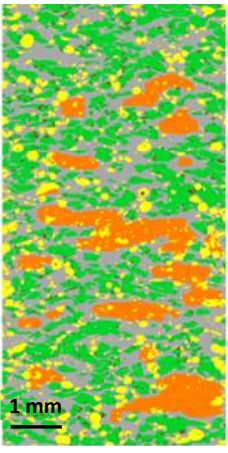

(b)

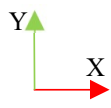

(c)

Figure 5. Spatial constituent distribution in M2

$3 \mathrm{D}$ visualization, 2D longitudinal visualization in $\mathrm{XZ}$ plane, 2D orthogonal visualization in $\mathrm{XYplane}$

Fiber bundles (orange), carbonaceous particles (green), matrix (gray), shots (yellow), voids (red)

These observations are confirmed by Figure 6 . The latter presents the spatial distribution of components using the area fraction of each component relative to the entire cross-section area XY versus the longitudinal sample location for M1 [20]. Fluctuations of component spatial distribution of M1, especially fiber entanglements and matrix, appear to be more important than those revealed for M2. This is confirmed by the standard deviations $(\sigma)$ of 6.8 and 3.43 for M2, compared to 5.16 and 2.59 for M1 of fiber entanglements and matrix respectively (Figure 6 and Figure 7).

The calculated fiber entanglement volume fraction (Fv) for M2 (10.29\%), given by Figure 7, is somewhat higher than that obtained for M1 (7.09\%), consistent with the poor fiber dispersion due to the short mixing time. It can be noted that the void volume fraction of $1.15 \%$ is double the void volume fraction of M1 $(0.55 \%)$. The higher presence of these voids is consistent with the cohesive defects at the constituent interfaces with the matrix revealed by the microstructural analysis. These results agree with the 2D analyses, the reduced mixing time resulted in a very heterogeneous microstructure. Although the constituents were pre-coated with resin, their cohesion at the interfaces with the matrix is slightly worse than that obtained for M1. 


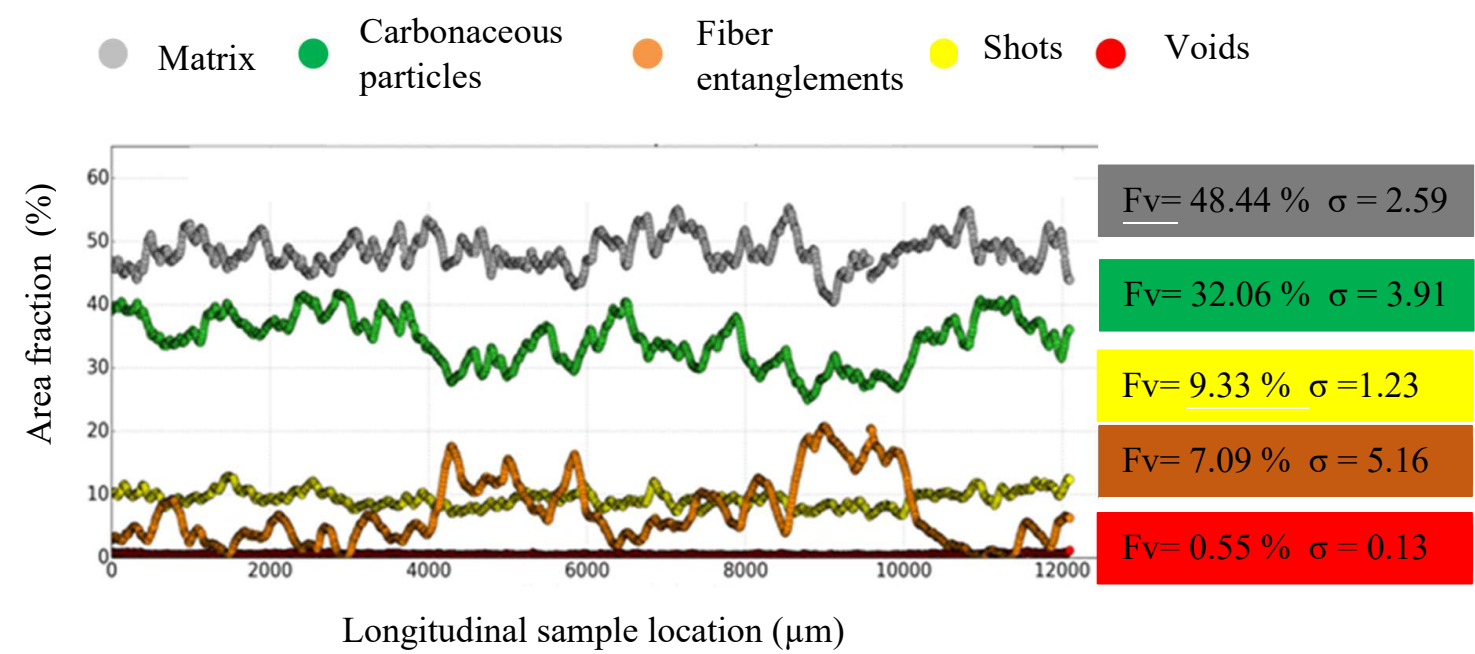

Figure 6. Spatial constituent distribution according to the longitudinal location (Z-axis) along the sample in M1 with volume fraction (Fv) and standard deviation $(\sigma)$ of each constituent
Matrix
Carbonaceous
Fibre particles
entanglements
Shots Voids

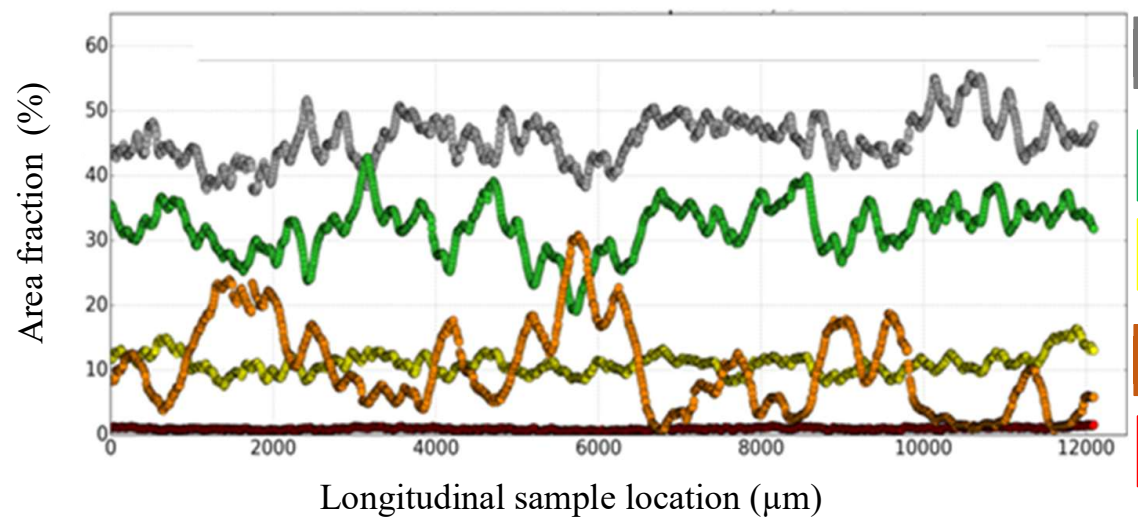

$\mathrm{Fv}_{\mathrm{V}}=45.73 \% \quad \sigma=3.43$

$\mathrm{Fv}=32.06 \% \quad \sigma=3.9$

$\mathrm{F}_{\mathrm{V}}=10.99 \% \quad \sigma=1.56$

$\mathrm{Fv}=10.29 \% \quad \sigma=6.8$

Figure 7. Spatial constituent distribution according to the longitudinal location (Z-axis) along the sample in M2 with volume fraction (Fv) and standard deviation $(\sigma)$ of each constituent

Figure 8 shows the spatial distribution of carbonaceous particles for the two M2 samples compared to that obtained for the two M1 samples. It can be noticed that the area fractions obtained for the two M2 samples do not overlap, which means that the size of the samples taken is insufficient to be representative of the distribution of carbonaceous particles. This confirms the very high heterogeneity of the microstructure of M2, mainly induced by the random distribution and the very large size of the fiber entanglements. 


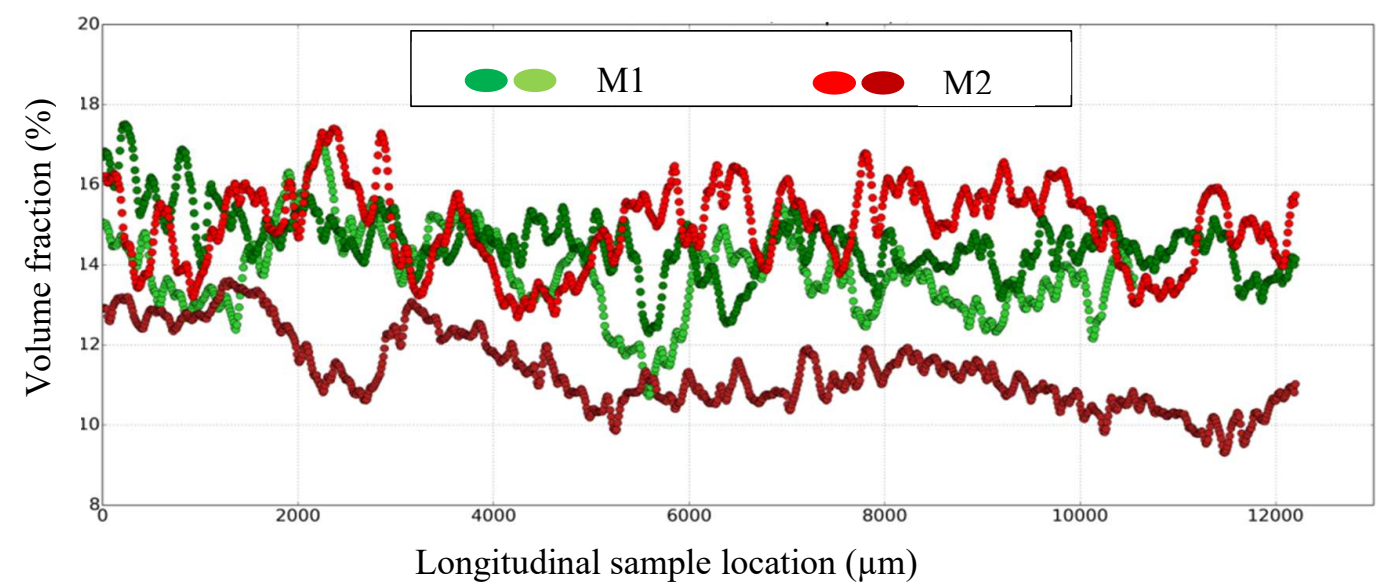

Figure 8. Spatial carbonaceous particle for two $16 \mathrm{~mm}$ diameter specimens sampled from M1 and M2 distribution

\subsection{Thermo-physical properties}

Results of thermo-physical characterizations of the two studied materials are given in Table 3. They show a higher density and a lower porosity for M1 compared to M2. This can be explained by the presence of voids induced by the lack of cohesion between the matrix/fiber entanglement interfaces in M2.

Table 3. Thermo physical properties of M1 and M2

\begin{tabular}{ccc} 
& M1 & M2 \\
\hline Density $\left(\mathrm{kg} \cdot \mathrm{m}^{-3}\right)$ & $1980(2)$ & $1950(3)$ \\
\hline Porosity $(\mathrm{Vol} \%)$ & 13.1 & 14.2 \\
\hline $\begin{array}{c}\text { Thermal Conductivity } \lambda\left(\mathrm{W} \cdot \mathrm{m}^{-1} \cdot \mathrm{K}^{-1}\right) \\
\text { Capacité thermique massique } \\
\mathrm{Cp}\left(\mathrm{J} \cdot \mathrm{kg}^{-1} \cdot \mathrm{K}^{-1}\right)\end{array}$ & $1.18(0.03)$ & $1.37(0.04)$ \\
\hline Thermal effusivity $\varepsilon\left(\mathrm{J} \cdot \mathrm{K}^{-1} \cdot \mathrm{s}^{-1 / 2} \mathrm{~m}^{-2}\right)$ & $847(2)$ & $851(5)$ \\
\hline $\begin{array}{l}\text { Coefficient of thermal expansion in } \\
\text { normal direction } \alpha\left(10^{-6} \mathrm{~K}^{-1}\right)\end{array}$ & $18.7(0.1)$ & 1520 \\
\hline
\end{tabular}

These results are in agreement with Maleque and Atiqah [26] who found that the material porosity decreases with increase of density value due to the presence of voids. Regarding thermal and thermally induced properties, thermal conductivity and thermal expansion show significant differences between the two materials while thermal effusivity, and heat capacity are comparable for both. As microstructural analysis showed in " 3.1 section », rockwool fibers present less cohesion with the matrix compared to M1. In fact, fibers in M2 are mostly found to be partially embedded in the matrix. 
This present an important factor which impacts thermal expansion. Indeed, a high cohesion allows the rockwool fibers to block the thermal expansion while a low cohesion leads fibers to slip in the matrix during its thermal expansion and thus facilitates the thermal expension. This may justify the lower coefficient of thermal expansion of M1.

The microstructure of M2, which presents higher thermal conductivity, is strongly influenced by entanglements, with microstructural heterogeneity becoming more pronounced the larger and more numerous the entanglements are. In this material, the distribution of carbonaceous particles, namely graphite (conductive particles), constrained in small inter-entanglement spaces, forms dense networks where the inter-particle spaces are reduced, which enhances thermal conductivity. This can explain the higher thermal conductivity of M2. These results agree with the work of $[15,27,28]$. These authors confirm that the distribution of constituents, especially fibers, has an influence on the thermal properties of composite materials.

\subsection{Mechanical properties}

Figure 9 shows that strain localizations correspond to the voids induced by the fiber entanglements, as well as to the rubber and graphite particles that are not very stiff in comparison with the other constituents [21]. These fiber entanglements may contain porosities. While for M2, bigger fiber bundles deform with a higher amplitude (in darker blue) (Figure 9 (b) and (d)). 

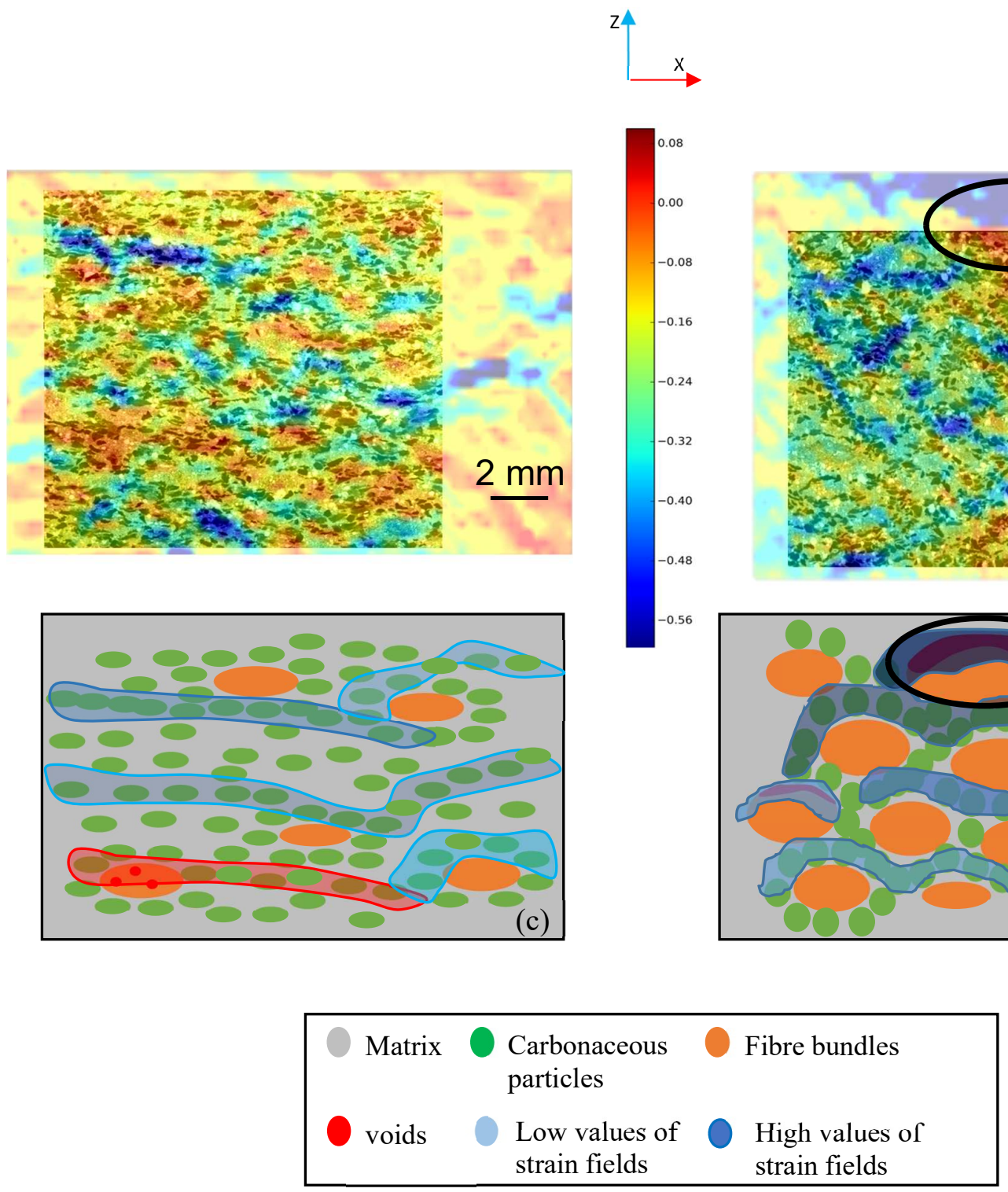

Figure 9. Strain fields Ezz (\%) in the compression direction for $10 \mathrm{MPa}$ superimposed on the microstructure for (a) M1 and (b) M2 and schematic relationship with constituent distribution for (c) M1 and (d) M2

Besides, Figure 9 (b) and (d) reveals a high amplitude deformation localization at a large surface entanglement of the M2 sample (circled in black), which may present voids and lack of cohesion at the interfaces with the matrix. Load transfer at these weakly cohesive interfaces is a factor in heterogeneous strain accumulation [29]. Lower amplitude localizations (light blue) are observed at some entanglements of M1 and M2, which could be attributed to porosities. For M1, only a few entanglements undergo weak compression (in red and light blue) (Figure 9 (a) and (c)). Other high amplitude localizations, oriented perpendicular to the loading direction, correspond to the clustering of rubber and graphite particles (dark blue). The localizations are stronger and more developed and (in darker blue), in the case of M2, as the density of carbonaceous particles in these clusters is higher for this material. 
Table 4. Compressive modulus defined for different stress levels of M1 and M2

Compressive modulus ( $\mathrm{MPa})$

\begin{tabular}{ccc}
\hline Stress levels & M1 & M2 \\
\hline $2 \mathrm{MPa}$ & 5515 & 2950 \\
\hline $5 \mathrm{MPa}$ & 5645 & 3465 \\
\hline $10 \mathrm{MPa}$ & 6100 & 5385
\end{tabular}

According to Table 4, we can notice that compressive modulus values increase with stress levels. This may be explained by the presence of porosities in these materials. Indeed, at the lower solicitation ( 2 $\mathrm{MPa}$ ), voids that are slightly compressed, close partially. As the load increases, compression closes more voids, which induces stiffness rise [25].

Considering the modulus obtained for M2, Table 9 reveals that they are lower compared to the compressive modulus of M1. According to several studies [30, 31], the mechanical properties of fiberreinforced composites depend, on the one hand, on the length of the fibers, their orientation and distribution in the material [26], and, on the other hand, on the shear strength of the interface between the fibers and the matrix. It should be noted that the structural integrity of the composite material and the ability of the interphase to transmit the load from the matrix to the embedded fibers is ensured by the shear strength of the fiber-matrix interface. These results are in accordance with $[32,33]$ who show that strength of composite materials depends on properties of reinforcing fibers and the quality of fibermatrix interfacial adhesion strength. They revealed that the applied load can be transferred from the matrix to fiber more efficiently when fiber-matrix adhesion strength is well established. When the fibermatrix cohesion is strong, better mechanical behavior of the material is obtained $[34,35,36]$. For the materials M1 and M2, microstructural analyses showed a better cohesion of the interface between the fibers and the matrix for M1. This justifies the lower compressive modulus found for M2. Besides higher porosity revealed in M2 in «3.1.1. section » can explain its lower compressive modulus [37].

\subsection{Tribological Behavior Analysis}

\subsubsection{Friction Behavior}

Figure 10 shows a comparable overall evolution of friction, which differs in their variation over time. These variations are generated by contact evolutions related to the formation and circulation of the third body at the interface. Figure 10 (a) shows that friction coefficient evolution of M1 appears to be more regularly continuous with an almost stable friction coefficient around 0.4-0.45. For M2, friction coefficient presents fluctuations with higher amplitude and presents a sudden decrease at $166 \mathrm{~s}$, which may be induced by the large and irregular size and distribution of fiber entanglements on the friction surface. 


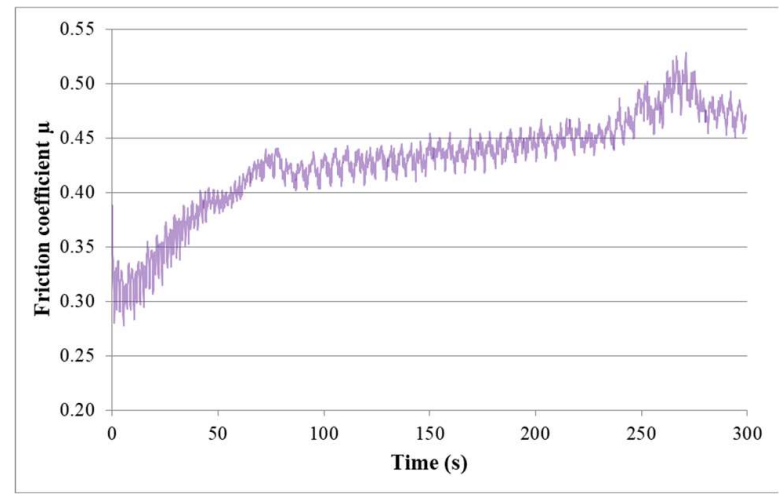

(a)

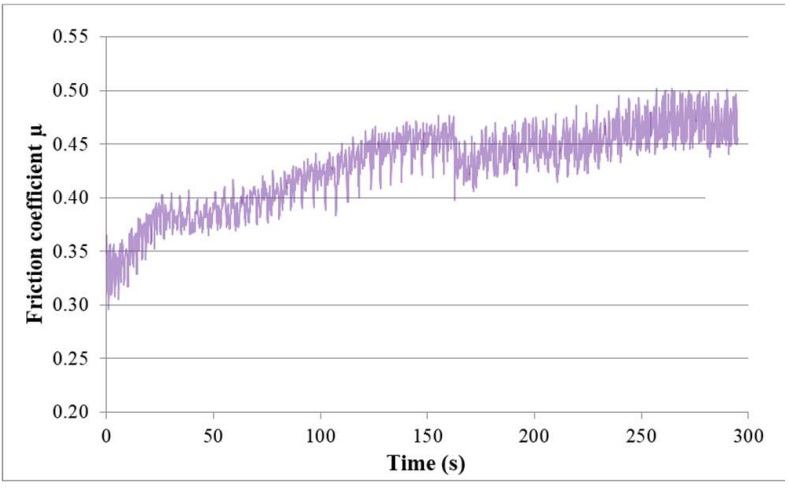

(b)

Figure 10. Friction coefficient evolution for (a) M1 and (b) M2

\subsubsection{Wear behavior}

EDS analyses reveal that the weight proportions of silicon, aluminum and magnesium are more important for M2. It should be noted that theses chemical components derive mainly from fibers and shots of rockwool. Consequently, secondary load-bearing plateaus of M2 include more debris of rockwool fibers. The lack of cohesion revealed at fiber/matrix interface could be the origin of the important pullout of rockwool fibers and thus their great amount in the third body [35, 38].

Table 5. Chemical composition of third body in load-bearing plateaus of M1 and M2 (wt \%)

\begin{tabular}{cccccc} 
& $\mathrm{C}$ & $\mathrm{O}$ & $\mathrm{Si}$ & $\mathrm{Al}$ & $\mathrm{Mg}$ \\
\hline $\mathrm{M} 1$ & 13.69 & 28.48 & 8.71 & 4.04 & 1.14 \\
\hline M2 & 14 & 25.66 & 12.9 & 6.01 & 1.93
\end{tabular}

The thickness of the pins is measured before and after friction tests as an indicator of wear, expressed as the thickness loss per unit time (Table 6). It can be noticed that the wear rate is higher for M2 with $2.69 * 10^{-5} \mathrm{~mm} / \mathrm{s}$ compared to $1.07 * 10^{-5} \mathrm{~mm} / \mathrm{s}$ for M1. This may be related to the lack of cohesion at the matrix-rockwool fiber interfaces for M2. This result agrees with the work of Ozturk and Satapathy on the impact of the quality of the fiber-matrix interface on the wear performance of friction materials $[30,39]$.

According to Chen et al. [40], when the composite material has lower compressive strength and higher fiber/matrix interfacial strength, it favors formation of friction layer and leads to higher and more stable friction properties. 
Table 6. Wear rate indicator (thickness loss per unit time) calculated for M1 and M2

\begin{tabular}{cc} 
Materials & Wear rate $(\mathrm{mm} / \mathrm{s})$ \\
\hline M1 & $1.07 * 10^{-5} \mathrm{~mm} / \mathrm{s}$ \\
\hline M2 & $2.69 * 10^{-5} \mathrm{~mm} / \mathrm{s}$
\end{tabular}

\subsubsection{Worn surface analysis}

SEM micrographs of worn surface of M2 (Figure 11) display fewer number of secondary third-body plateaus and less extended than those of M1. Besides, worn surfaces of M2 reveal the presence of coarse debris, trapped in big porosities induced by fiber entanglements (Figure 12(b)) and the lack of cohesion in fiber/matrix interface (Figure 13(b)). These debris result probably from the destruction of the secondary plateaus. All these observations indicate that M2 is less prone to develop and preserve a regular layer of third body in the contact, unlike M1. In fact, the pin surface of M1 is more covered with third body layers which are well extended and uniformly distributed in the sliding direction (Figure 11 (a) and Figure 13 (a)). The secondary load-bearing plateaus are generated by third body compaction under the combined action of normal pressure and shear force as shown in Figure 12 (a) [41, 42].

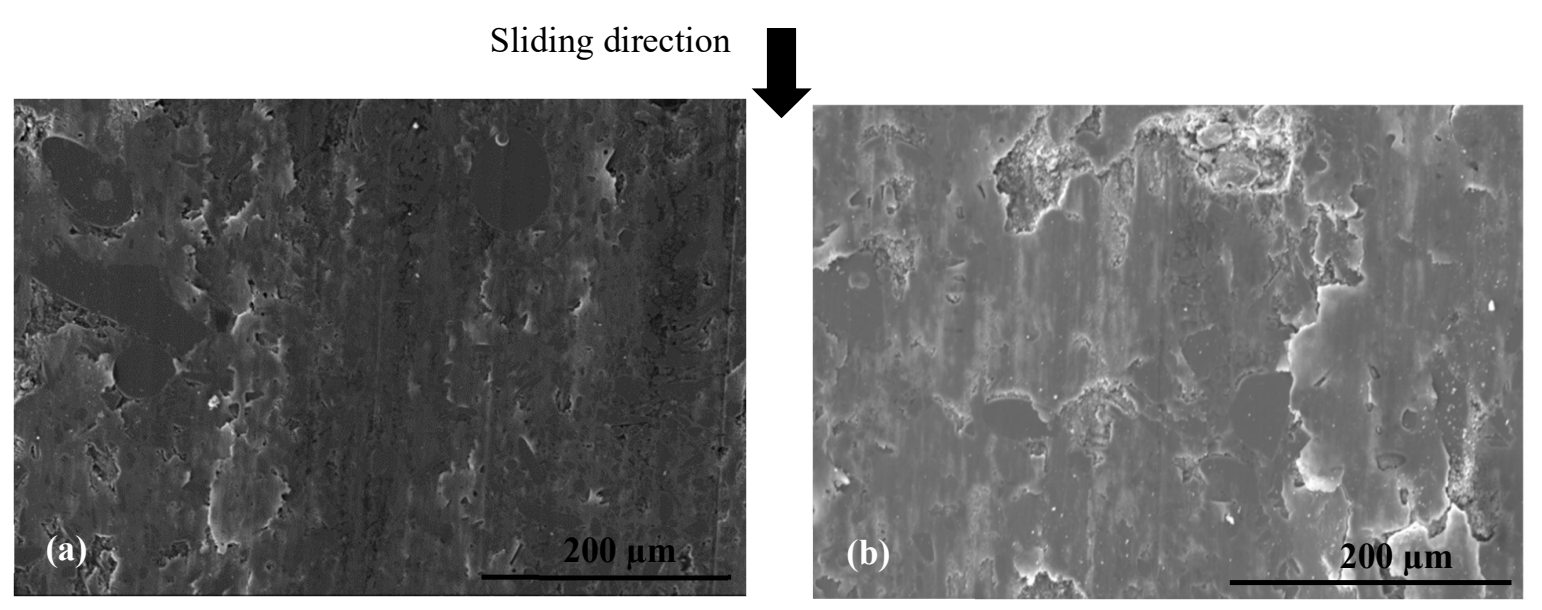

Figure 11. Secondary plateaus revealed in the rubbed surfaces of (a) M1 and (b) M2 (SEM, SE)

In the present study, the interfacial adhesion between rockwool fibers and matrix in M1 is found to be superior to that of M2. This explains the more stable friction coefficient and the higher wear resistance of M1. These results are consistent with previous works $[41,43]$ which report that the improved adhesion between fibers and matrix inhibits the pullout and removal of rockwool fibers from the matrix during friction process. In other words, the quality of fiber matrix interface guarantees the reinforcing efficiency of the fibers. However, relatively weak interface bonding strength between rockwool fibers and matrix generates fiber debonding under normal pressure. Consequently, this leads to the deterioration of the stress transfer in the matrix and affects the wear resistance performance. 


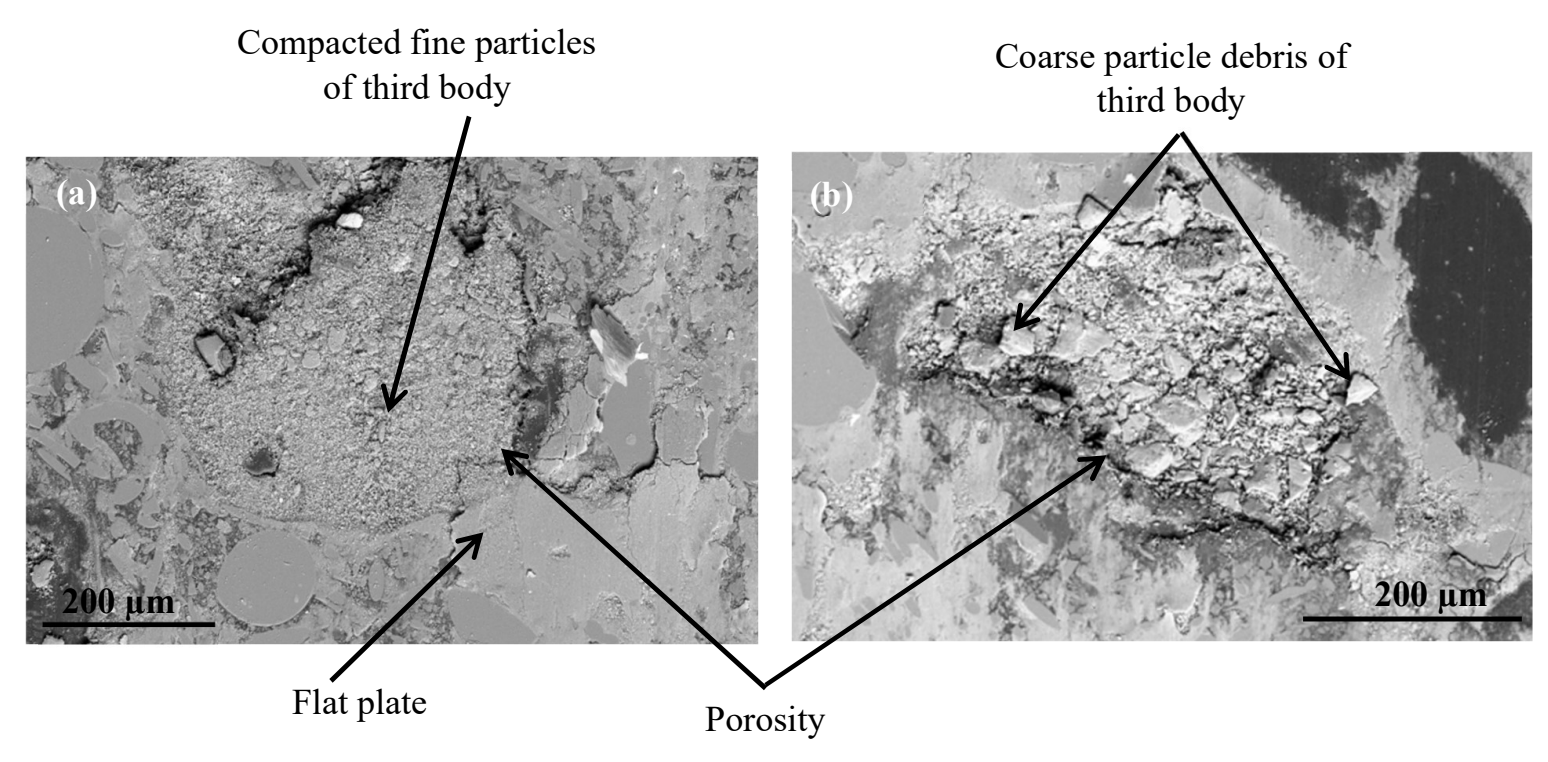

Figure 12. SEM micrographs of worn surfaces of (a) M1 and (b) M2 (BSE)

Moreover, in terms of the stability of load-bearing plateaus, Figure 11 (a) and Figure (13 (a) confirms that M1 constituent distribution is more prone to form stable secondary plateaus, which further explains its better tribological behavior than M2. Theses results contribute to a better understanding of the link between microstructural characteristics and tribological behavior of composite friction materials.
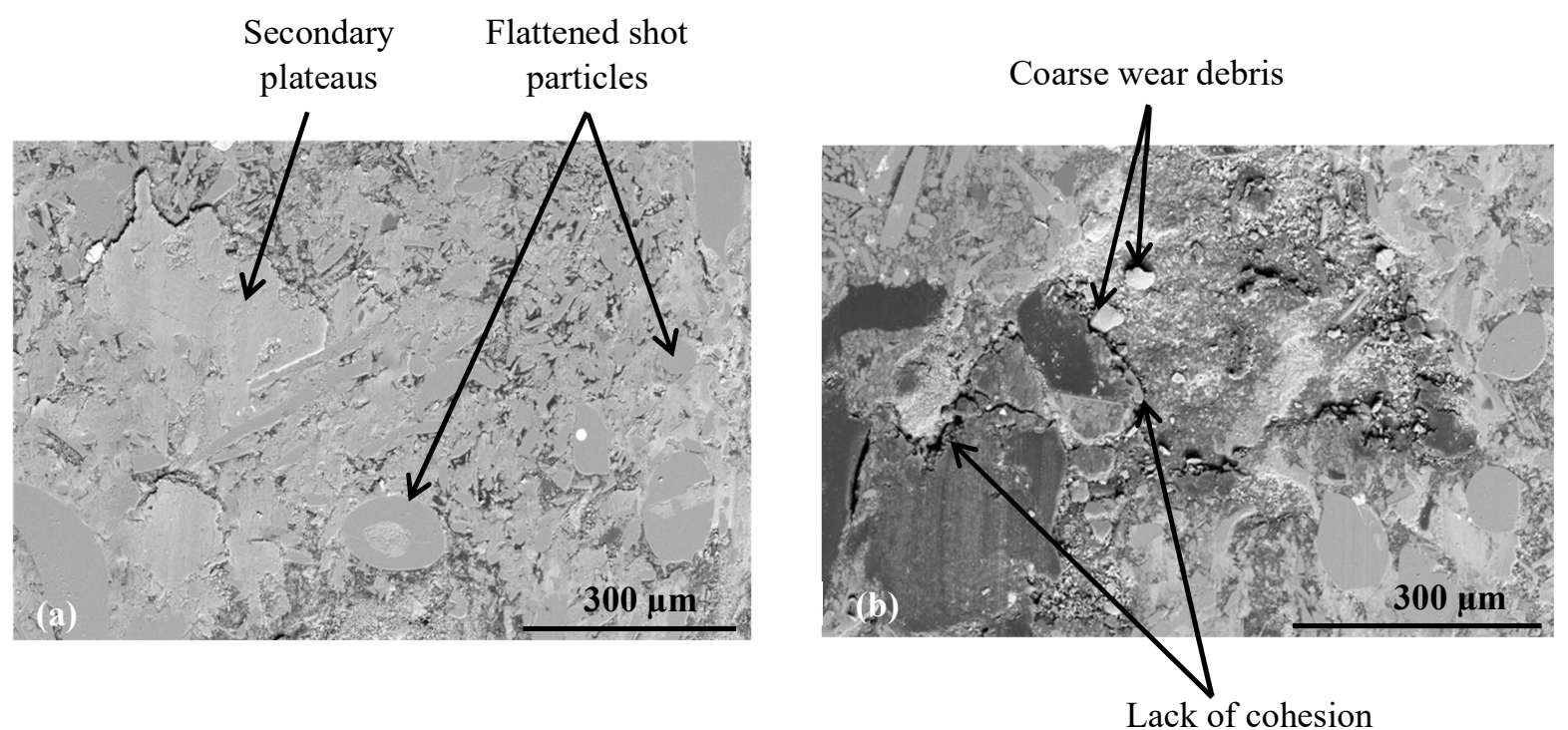

Figure 13. SEM observations of the third body distribution of materials (a) M1 and (b) M2 (BSE) 
From all theses analyses, it can be concluded that the improved tribological behavior of M1 may be related to the superior fiber-matrix interfacial adhesion and the stable secondary third-body plateaus formed on the friction surfaces, which is consistent with the previous reports on fiber-reinforced friction composites $[7,44,45]$.

\subsubsection{Mass temperature}

As it was indicated, K-type thermocouples were used to measure the disc and pin mass temperature from $2 \mathrm{~mm}$ to the friction surface. Table 7 summarizes pin and disc temporal mass-temperature variation during sliding test for the M1 and M2 materials. Results of the temperature variation of the pins of the two materials are comparable. However, the disc heats up more when rubbed against M2 compared to M1. In this case, the surface temperature variation is driven by the thermal contact resistance, which depends in particular on the third body layer at the interface, and not by a difference in terms of thermal effusivity of the materials, since their values are found to be close (Table 3). This observation is consistent with the analyses of pins rubbed surface. The secondary plateaus of third body are more numerous in the case of M1 compared to M2, which may lead to a higher thermal resistance and explain the decrease of the disc temperature [46].

Table 7. Pin and disc temporal mass-temperature variation for M1 and M2

\begin{tabular}{ccc} 
& $\Delta \mathrm{T} \operatorname{disc}\left({ }^{\circ} \mathrm{C}\right)$ & $\Delta \mathrm{T} \operatorname{pin}\left({ }^{\circ} \mathrm{C}\right)$ \\
\hline $\mathrm{M} 1$ & 20 & 17.1 \\
\hline $\mathrm{M} 2$ & 23.3 & 16
\end{tabular}

\section{Conclusions}

This paper focused on the impact of mixing duration on microstructure, thermo-physical and mechanical properties and tribological behavior of organic composite friction materials. Several synergies between constituents were highlighted and correlated to properties, friction behavior and wear mechanisms.

This study contributes to a deeper understanding and a better mastering of the link between microstructural characteristics, namely porosity, interface defects and constituent arrangement and distribution in the material, with thermo-physical and mechanical properties and tribological behavior. It demonstrates the necessity to consider these materials as multi-constituent and interdependent systems and explore the different synergies between constituents.

It was concluded that :

- Longer mixing duration permits to establish a better interface between matrix and constituents, namely rockwool fibers and rubber, and more homogeneous constituent distribution thus improves physical (higher density), thermal (reduce thermal expansion), mechanical (higher compressive modulus) properties and tribological (more stable friction) and wear (higher wear and thermal resistance).

- Fiber entanglements size and arrangement induced by mixing duration impact conductive carbonaceous particles distribution and thus affects thermal conductivity.

- Porosities, induced by the lack of cohesion between fiber entanglements and matrix, presenting large and irregular size and distribution on the friction surface, generate 
higher strain localizations, involve an irregular supplying of the tribological system, which disrupts load-bearing mechanisms.

\section{Acknowledgements}

This work is part of thesis MOBIDOC funded by the European Union under the PASRI program. The authors thank the Ministry of Higher Education and Scientific Research in Tunisia, the Ministry of Foreign Affairs in France .The National Center for Scientific Research, and the Joint Committee of University Cooperation for their support for cooperation between the Laboratoire de Mecanique Multiphysique Multiéchelle at the University of Lille and the Laboratoire des Systemes Electro-Mecaniques at the University of Sfax. The authors gratefully acknowledge the International Campus on Safety and Intermodality in Transportation (CISIT), the Nord-Pas-deCalais Region, the European Community, the Regional Delegation for Research and Technology, the Ministry of Higher Education and Research, and the National Centre for Scientific Research for their continued support of research on braking by friction at Laboratoire de Mecanique Multiphysique Multiéchelle. Special thanks are also due to the STUGAFREM Society (Tunisia) for providing us with the brake lining samples. The authors also gratefully acknowledge the helpful comments and suggestions of the reviewers, which have improved the presentation.

\section{References}

[1] Filip P.,Weiss Z. Rafaja D. On friction layer formation in polymer matrix composite materials for brake applications. Wear 2002, 252, 189-198.

https://doi.org/10.1016/S0043-1648(01)00873-0

[2] Rajan B.S., Balaji M.A.S., Noorani A.B.M.A., Khateeb M.U.H.,Hariharasakthisudan P.,Doss P.A. Tribological performance evaluation of newly synthesized silane treated shell powders in friction composites. Materials Research Express 2019, 6, 065317.

[3] Ji Z., Luo W., Zhou K., Hou S., Zhang Q., Li J., Jin H. Effects of the shapes and dimensions of mullite whisker on the friction and wear behaviors of resin-based friction materials. Wear 2018, 406, $118-125$.

https://doi.org/10.1016/j.wear.2018.03.018

[4] Singh T.,Tiwari A., PatnaikA., Chauhan R.,Ali S. Influence of wollastonite shape and amount on tribo-performance of non-asbestos organic brake friction composites. Wear 2017, 386, 157-164.

https://doi.org/10.1016/j.wear.2017.06.011

- [5] Han Y,TianX,YinY. Effects of ceramic fiber on the friction performance of automotive brake lining material. Tribology Transactions 2008, 51, 779-83.

https://doi.org/10.1080/10402000802011778

[6] Lu Y., Tang C-F., Wright MA. Optimization of a commercial brake pad formulation. Journal of Applied Polymer Science 2002, 84, 2498-2504

https://doi.org/10.1002/app.10606

[7] Matejka V., Fu Z.Z., Kukutschova J, Qi S.C., Jiang S.L., Zhang X.A, Yun R.P., Vaculik M., Heliova M., Lu YF. Jute fibers and powderized hazelnut shells as natural fillers in non-asbestos organic non-metallic friction composites. Materials and Design 2013, 51, 847-53.

https://doi.org/10.1016/j.matdes.2013.04.079 
[8] Satapathy BK, Bijwe J. Composite friction materials based on organic fibers: sensitivity of friction and wear to operating variables. Composites Part A: Applied Science and Manufacturing 2006, 37, $1557-67$.

https://doi.org/10.1016/j.compositesa.2005.11.002

[9] Ertan R., Yavuz N. An experimental study on the effects of manufacturing parameters on the tribological properties of brake lining materials. Wear 2010, 268, 1524-1532.

https://doi.org/10.1016/j.wear.2010.02.026

[10] Kim S.J., Kim K.S., Jang H. Optimization of manufacturing parameters for a brake lining using Taguchi method. Journal of Materials Processing Technology 2003, 136, 202-208.

https://doi.org/10.1016/S0924-0136(03)00159-6

[11] Öztürk B., Öztürk S., Adem A. Adigüzel. Effect of Type and Relative Amount of Solid Lubricants and Abrasives on the Tribological Properties of Brake Friction Materials. Tribology Transactions 2013, 56:3, 428-441.

https://doi.org/10.1080/10402004.2012.758333

[12] Vineeth Kumar V. and Senthil Kumaran S. Friction material composite: types of brake friction material formulations and effects of various ingredients on brake performance-a review. Materials

Research Express 2019, 6, 082005.

https://doi.org/10.1088/2053-1591/ab2404

[13] Kim S.J, Cho MH, Lim DS, Jang H. Synergistic effects of aramid pulp and potassium titanate whiskers in the automotive friction material. Wear 2001, 251, 1484-91.

https://doi.org/10.1016/S0043-1648(01)00802-X

[14] Wu, S., Zhao, J., Guo, M.; Zhuang, J., Wu, Q. Effect of Fiber Shape on the Tribological, Mechanical, and Morphological Behaviors of Sisal Fiber-Reinforced Resin-Based Friction Materials: Helical, Undulated, and Straight Shapes. Materials 2021, 14, 5410.

https://doi.org/10.3390/ma14185410

[15] Makni F., Kchaou M., Cristol A.-L., Elleuch R., and Desplanques Y., A new method of mixing quality assessment for friction material constituents toward better mechanical properties, Powder Metallurgy and Metal Ceramics 2017 , vol.56, 1-13

https://doi.org/10.1007/s11106-017-9864-X

[16] Hentati N., Kchaou M., Cristol A-L., Elleuch R., and Desplanques Y. Impact of hot molding temperature and duration on braking behavior of friction material. Proc Instit Mech Eng. Part J:

Journal of Engineering Tribology 2019, 135065011987378, 1-9.

https://doi.org/10.1177/1350650119873789

[17] Hentati N., Kchaou M., Cristol A-L., Najjar D., Elleuch R. Impact of post curing duration on the mechanical, thermal and tribological behavior of an organic friction material. Materials Design 2014, 63, 699-709.

https://doi.org/10.1016/j.matdes.2014.06.010

[18] Rupiyawet K., Kaewlob K., Sujaridworakun P., Buggakupta W. Optimization of Mixing Conditions on the Physical and Tribological Properties of Brake Pads. Key Engineering Materials 2019, 824, 67-72.

https://doi.org/10.4028/www.scientific.net/KEM.824.67 
[19] Baklouti M., Elleuch R., Cristol A-L., Najjar D., Desplanques Y. Relationships between the heterogeneous microstructure, the mechanical properties and the braking behavior of an organic brake lining material. Proceedings of the Institution of Mechanical Engineers, Part D Journal of Automobile Engineering 2013, 227, 549-560.

https://doi.org/10.1177/0954407012461751

[20] Makni F., Cristol A.-L., Kchaou M., Elleuch R. and Desplanques Y. Synergistic effects of fiber arrangements on the microstructure and properties of organic composite materials. Journal of Composite Materials 2020, 54(29), 4621-4634.

https://doi.org/10.1177/0021998320933939

[21] Makni F. Hétérogénéité microstructurale de garniture de frein: lien avec les proprietés thermo physiques et mécaniques et le comportement tribologique. Doctoral Thesis, Centrale Lille, Université de Sfax, Tunisia, 2017.

[22] Buffiere J.-Y., Maire E., Adrien J., Masse J.-P., Boller E. In situ experiments with X ray tomography: an attractive tool for experimental mechanics. Experimental Mechanics 2010, 50, 289305.

https://doi.org/10.1007/s11340-010-9333-7

[23] Zhang J., Cai Y., Ye W., Yu T.X. On the use of the digital image correlation method for heterogeneous deformation measurement of porous solids. Optics Lasers Engineering 2011, 49, 200 209.

https://doi.org/10.1016/j.optlaseng.2010.09.015

[24] Zhang GP., Volkert C.A., Schwaige R., Mönig R., Kraft O. Fatigue and thermal fatigue damage analysis of thin metal films. Microelectron Reliability 2007, 47(12), 2007-2013.

https://doi.org/10.1016/j.microrel.2007.04.005

[25] Baklouti M., Cristol A-L., Desplanques Y., Elleuch R. Impact of the glass fiber addition on tribological behavior and breaking performances of organic matrix composites for brake lining. Wear 2015, 330-331, 507-514.

https://doi.org/10.1016/j.wear.2014.12.015

[26] Maleque M. and Atiqah A.Development and Characterization of Coir Fiber Reinforced Composite Brake Friction Materials, Arabian Journal for Science and Engineering 2013, 38, 3191-99 https://doi.org/10.1007/s13369-012-0454-4

[27] Lei H.F., Zhang Z.Q. and Liu B. Effect of fiber arrangement on mechanical properties of short fiber reinforced composites. Composites Science and Technology 2012, 72, 506-514

https://doi.org/10.1016/j.compscitech.2011.12.011

[28] Moigne N.L. van den Oever M. and Budtova T. A statistical analysis of fiber size and shape distribution after compounding in composites reinforced by natural fibers. Composites Part A Applied Science and Manufacturing 2011, 42, 1542-1550.

https://doi.org/10.1016/j.compositesa.2011.07.012

[29] Godara A., Raabe D. Influence of fiber orientation on global mechanical behavior and mesoscale strain localization in a short glass-fiber-reinforced epoxy polymer composite during tensile

deformation investigated using digital image correlation, Composites Science and Technology 2007, $67,2417-2427$.

https://doi.org/10.1016/j.compscitech.2007.01.005 
[30] Scheider I., Chen Y.Hinz A., Huber N., Mosler J. Size effects in short fibre reinforced composites. Engineering Fracture Mechanics 2013,100, 17-27.

https://doi.org/10.1016/j.engfracmech.2012.05.005

[31] Ozturk B., Ozturk S. Effects of Resin Type and Fiber Length on the Mechanical and Tribological Properties of Brake Friction Materials. Tribology Letters 2011, 42, 339-350.

https://doi.org/10.1007/s11249-011-9779-5

[32] Jae Hyun G., Byung S.J., Ho J. The effect of short glass fiber dispersion on the friction and vibration of brake friction materials. Wear 2016, 362-363, 61-67

https://doi.org/10.1016/j.wear.2016.05.04

[33] Cox R.L. Engineered Tribological Composites: The Art of Friction Material Development, SAE International, 2011, ISBN of 978-0-7680-3485-1

[34] Bilger N. A micromechanical analysis of the role of particle clustering on the brittle-ductile transition in nuclear steels, Thèse de Doctorat, Ecole Polytechnique, Palaiseau (France), October 2003.

- [35] Tze W.T.Y., Gardner D.J., Tripp C.P., Neill S.C. O. Cellulose fiber/polymer adhesion: effects of fiber/matrix interfacial chemistry on the micromechanics of the interphase. Journal of Adhesion Science and Technology 2006, 20(15), 1649-1668.

https://doi.org/10.1163/156856106779024427

[36] Zamanzade M., Stommel M., Schoneich M. Fiber-matrix interphase in applied short glass fiber composites determined by a nano-scratch method. Composites Science and Technology 2015, 119, 100-107.

https://doi.org/10.1016/j.compscitech.2015.10.004

[37] Hyung C., Seong J.K, Daehwan K., Ho J. Effects of ingredients on tribological characteristics of a brake lining: an experimental case study. Wear 2005, 258, 1682-1687.

https://doi.org/10.1016/j.wear.2004.11.021

- [38] Heng J.Y.Y., Pearse D.F., Thielmann F., Lampke T. Bismarck A. Methods to determine surface energies of natural fibers: a review. Composite Interfaces 2007, 14, 581-604.

https://doi.org/10.1163/156855407782106492

[39] Satapathy B. and Bijwe J. Analysis of simultaneous influence of operating variables on abrasive wear of phenolic composites. Wear 2002, 253 787-94.

https://doi.org/10.1016/S0043-1648(02)00158-8

[40] Chen T., Gong W., Liu G. Effects of fiber-types on braking behavior of carbon-carbon composites. Materials Science and Engineering, 2006 441, 73-78.

https://doi.org/10.1016/j.msea.2006.08.101

[41] Wu S., Zhao J., Guo M., Zhuang J., Wu Q. Effect of Fiber Shape on the Tribological, Mechanical, and Morphological Behaviors of Sisal Fiber-Reinforced Resin-Based Friction Materials: Helical, Undulated, and Straight Shapes. Materials 2021, 14, 5410.

https://doi.org/10.3390/ma14185410

[42] Ho S.C., Chern Lin J.H., Ju C.P. Effect of fiber addition on mechanical and tribological properties of a copper/phenolic-matrix friction material. Wear 2005, 258, 861-9. 
https://doi.org/10.1016/j.wear.2004.09.050

[43] Wang Z., Hou G., Yang Z., Jiang Q., Zhang F., Xie M., Yao Z. Influence of slag weight fraction on mechanical, thermal and tribological properties of polymer based friction materials. Materials Design 2016, 90, 76-83.

https://doi.org/10.1016/j.matdes.2015.10.097

[44] Cai P., Li Z., Wang T., Wang Q. Effect of aspect ratios of aramid fiber on mechanical and tribological behaviors of friction materials. Tribology International 2015, 92, 109-16.

https://doi.org/10.1016/j.triboint.2015.05.024

[45] Rasheva Z., Zhang G., Burkhart T. A correlation between the tribological and mechanical properties of short carbon fibers reinforced PEEK materials with different fiber orientations. Tribology International 2010, 43(8),1430-7.

https://doi.org/10.1016/j.triboint.2010.01.020

[46] Majcherczak D., Etude thermique d'un contact glissant : approche numérique et expérimentale, Thèse de doctorat, Université des Sciences et Technologies de Lille, 2003. 